\title{
Weighting environmental effects: Analytic survey with operational evaluation methods and a meta-method
}

\author{
Gjalt Huppes • Lauran van Oers • Ugo Pretato • \\ David W. Pennington
}

Received: 25 March 2011 / Accepted: 18 March 2012 /Published online: 3 May 2012

(C) The Author(s) 2012. This article is published with open access at Springerlink.com

\begin{abstract}
Purpose The purpose of this paper is to supply an open method for weighting different environmental impacts, open to basically different evaluation approaches and open to easy revisions. From the partial, diverse and conflicting weighing methods available, a most consistent and flexible meta-method is constructed, allowing for a transparent discussion on weighting.

Methods The methods incorporated are as general as possible, each single one being as pure as possible. We surveyed encompassing operational methods for evaluation, applicable in LCA and in larger systems like countries. They differ in terms of modelling, as to midpoint or as to endpoint; as to evaluation set-up, in terms of collective preferences or individual preferences; and as to being either revealed or stated. The first is midpoint modelling with collectively stated preferences, with operational weighting schemes from Dutch and US government applications. Second is the LCAtype endpoint approach using individual stated preferences, with public examples from Japan and the Netherlands. The third is the integrated modelling approach by economists.
\end{abstract}

Responsible editor: Alessandra Zamagni

This paper draws on the results of a project executed for the EC, Joint Research Centre (JRC), with contract number 384419.

G. Huppes $(\bowtie) \cdot$ L. van Oers

CML, Institute of Environmental Sciences, Leiden University,

PO Box 9518, 2300 RA, Leiden, The Netherlands

e-mail: huppes.cml@gmail.com

U. Pretato $\cdot$ D. W. Pennington

JRC-IES - European Commission, Joint Research Centre,

Institute for Environment and Sustainability,

Via E. Fermi 2749,

21027, Ispra, VA, Italy
Results All methods are internally inconsistent, as in terms of treatment of place and time, and they are incomplete, lacking environmental interventions and effect routes. We repaired only incompleteness, by methods transfer. Finally, we combined the three groups of methods into a metaweighting method, aligned to the ILCD Handbook requirements for impact assessment. Application to time series data on EU-27 consumption shows how the EU developed in terms of overall environmental decoupling.

Conclusions The disparate methods available all can be improved substantially. For now, a user adjustable metamethod is the best option, allowing for public discussion. A flexible regularly updated spreadsheet is supplied with the article.

Keywords Decoupling · Eco-efficiency ILCD impact assessment $\cdot$ Problem shifting $\cdot$ Weighting

\section{Introduction}

The core question in this paper is how environmental considerations can play a consistent role in practical decision making, covering all relevant effects of actions on the environment. Sustainability requires consistent choices regarding environmental effects also in relation to economic performance. Environmental quality should be achieved at lowest possible costs, or for given costs the environmental performance should be maximized. See the box example on how easy it is to deviate from this basic principle of rationality, in the sense of avoiding sub-optimality. Several approaches for overall evaluation have developed. We sketch the background to these developments and a way to come to a flexible but unified method, open to reasoned further development. 
Six decades ago, von Neumann and Morgenstern (1944) formulated requirements on rational decision making. A decision maker in a multi-attribute world is rational if his choices can be explained by at least one set of weights on each of the relevant effect types involved. How to decide in an optimal way became a main subject in the fifties and sixties, with the Arrow's (1950) impossibility theorem guiding the discussion: we cannot generally have optimality in multi-actor decision making. Sen (1970) has refined the requirements for avoiding sub-optimality, as by adding criteria like that outcomes of a choice process should not depend on the presence of irrelevant alternatives. The discussion has then broadened into what empirical criteria to use, including value-based criteria on distributional effects and justice. Rawls' (1971) difference strategy has been most influential, leading to the position that increased inequality may be justifiable as long as it benefits the poorest. In that discussion, the Brundtland sustainability criteria have come up, with emphasis on distribution within and between generations (Anonymous 1987), giving more precedence to justice than to welfare. With all these normative approaches, environmental effects and environmental quality play an indispensible role in the evaluation of options. In decision theory complex cases are referred to in terms of multiattribute situations (see, e.g., Scholz and Tietje 2002; Higgins et al. 2008).

Two decades ago, environmental analysis of products (goods and services) developed as LCA, with the operational definitions of environmental effects in terms of impact categories. The large number of interventions, i.e., emissions and extractions, related to a case study is called the inventory list. By the procedure of characterisation the interventions are aggregated into a limited number of impact categories. The modelling of the effects in terms of impact categories can be at a midpoint (state) or an endpoint (damage) level. These endpoint impact categories typically express indicators into three Areas of Protection (AoP), like human health, ecosystem health and resources. A recommended set of characterisation factors has recently been developed coordinated by the EC-JRC (see ILCD Handbook on LCIA; EC-JRC 2011, and the two earlier documents EC-JRC 2010a; EC-JRC 2010b). The AoP and impact categories are listed in Table 2. In this article, the characterisation is based on this ILCD recommended set of characterisation factors. The specification of endpoint effects can be much more uncertain and incomplete than midpoint modelling and generally has not been agreed upon let alone been standardised. So, the most reliable and detailed environmental information has often become available at midpoint impact category level. Both midpoint and endpoint scores are multiple scores. With operational models and data specifying these different dimensions, the problem of weighting came on the agenda. Overall judgements are required. Clearly, they are not a subject for empirical science but for normative evaluation.

One of the first quantified weighting exercises was in the Netherlands, where government officials in a panel agreed upon a set of preference based weights, in 1995, to be used in a Covenant with the Netherlands Oil and Gas Exploration and Production Association (NOGEPA), see Sas et al. (1996). An update of these weighting factors has been made in 2005, see Huppes et al. (2007), now being used in the meta-weighting method developed here, in one of the three basic options. It is combined with similar but later approaches from the US, BEES and EPA, both used in the realm of sustainable building (see Lippiatt 2007). The method of weighting by then was clear. Weights are ratio-scale attributes, with an overall score resulting from weighted addition. The necessary normalization to the same dimension is to be based on external normalization. This is in contrast to project based internal normalization as usual in other domains of decision theory. This choice fits the rationality criterion of Sen (1970) that the preferred outcomes should not depend on irrelevant alternatives. The case specific internal normalization may easily violate this criterion except in most simple cases. Formulated first by Heijungs et al. (1992), Norris (2001) showed the differences also with convincing examples. External normalization is to be used in LCA evaluation procedures for reasons of social rationality, for avoiding arbitrariness at a case level.

Finnveden (1997) asked the basic question: where are the values? In fundamental evaluation discussions, we ideally would link environmental effects to values. Hofstetter (1998) has been one of the early contributors to the discussion, showing how preferences differ between cultural perspectives, attitudes, and stakeholders, see also Mettier and Hofstetter (2005). Divergent approaches were coming up then already (see Notarnicola et al. 1998). Finnveden's question remained on the table as values relate to differences in preferences here, not to the items specified in the environmental effect scores. Value reasoned weighting has not yet been established. One answer came from Powell et al. (1997), who looked for sources of valuation as expressed by relevant groups in society, using representative panels. They avoid the cultural relativism of Hofstetter and look for authoritative answers, either from a democratic perspective as expressed preferences of "the people" or as expressed preferences of their representatives, governments. They also investigate the option of policy targets based weights, as public preferences, but indicate that the suppositions for using targets are so extreme as not being met in practice now and hardly to be met at all. The democratic approach remains then for them, as the willingness-to-pay or to accept the consequences of environmental interventions. This line of reasoning is the one used in cost-benefit analysis for specifying non-market effects. Results have been coming 
in based on increasingly sophisticated analysis. They are used in the meta-method as developed here as the second option, with results of the EU New Energy Externalities Development for Sustainability (NEEDS) project as a main basis, using integrated modelling (see Preiss et al. 2008). A third line of reasoning reduces the number of different items to weigh by advancing empirical modelling from midpoints to endpoints. The EcoIndicator 1999 is a main example (Goedkoop and Spriensma 2000), with later expansions in the ReCiPe project (see Heijungs 2008). The simplification of having a more limited number of effect categories is bought at a price though: there are fundamental limitations in validity and reliability of this modelling step. The weighting step, next, is ultimately based on a panel method, with persons or organizations expressing their preferences, as in the economists' approach. One difference with the integrated modelling methods of economists is that a time specification is lacking. The time horizons involved hence cannot play a role. Especially with long term effects as in climate change and eco-toxicity, differences with the economists approach may be substantial. As LCA is mostly not time-specified, there is an inconsistency here which cannot be avoided.

Many practical weighting sets have been developed combining different approaches and methods, and often using proxies to cover gaps in explicit value and preference statements. In selecting operational methods to be used in the meta-method several criteria play a role. First, we have tried to stick to pure types, to remain as open as possible to scrutiny on the validity and reliability of the results of the combined method, the meta-method. Second, we discarded methods using a single criterion to the exclusion of all other criteria. Third, we selected methods with a minimum of scientific robustness, as in not violating Sen's independence of irrelevant alternatives criterion. Finally, we focused on methods with some authoritative backgrounds and applications, as by governments. Midpoint methods from the LCA domain were clearly established, as are the economic valuation methods. Endpoint impact assessment methods linked to weighting are less developed, but constitute an interesting link between LCA midpoint and economic endpoint approaches. We decided to include some recently developed endpoint method, even though less clearly developed and less authoritative. To give an example on the selection process, the EPS method (Steen 1999a,b; see also Bengtsson and Steen 2000) uses a combination of hedonic pricing, contingent valuation and public expenditure and combines these with substantial corrections by the authors into one weighting method. Though used in practice, this method is not included in the operational set due to its diverse underlying methods.

We did not develop new methods but use existing methods for evaluation, expanding them somewhat for broad and comparable application in a most consistent way. Lundie and Huppes (1999) in a practical way tried to narrow down the range of weighting sets which might reasonably be applied. Softly, this narrowing down approach is followed here, by using basically different approaches in the metaweighting set. As this set is available in a free downloadable operational spreadsheet, the meta-weights can be set by the user (see Appendix 1). One default set is supplied for an easy starting application. For the moment this seems the most reasonable way to deal with the thousands of environmental interventions which are invoked in any technologies related decision. Though there will never be a final position in weighting, intermediate and preliminary positions are required to focus the discussion.

The meta-weighting method can be applied in the usual LCA product-function domain, by firms, NGOs, consumers and governments. But it may also be used for more aggregate applications, covering broader system, like energy systems, and more aggregate units like total consumption in a country or the total of all economic activities in a country, as with data supplied in environmentally extended InputOutput Analysis. We will focus on a most aggregate example here: total society. By applying it to yearly totals of environmental interventions we can measure the overall performance of society, similar to measuring national income. Combining these macro level applications we can establish in how far environmental performance and economic performance are decoupling. The corollary at a micro level would be ecoefficiency analysis, as environmental intensity.

Box: Decision making with complex economic and environmental effects

Simplified examples are difficult to understand and resolve already. Let us start with decision making in a simple situation. We have two options for environmental investments. One is increasing energy efficiency of waste incineration by high-temperature burners. The additional costs are $€ 1$ million per year, saving 30,000 tons of $\mathrm{CO}_{2}$ emissions, but increasing $\mathrm{NO}_{x}$ emissions by 2,000 tons, contributing to acid rain and eutrophication. The other option is to install improved DeNOx installations in the five existing electricity plants in the city. Each costs $€ 200,000$ per year in additional cost and leads to a reduction of 400 tons of $\mathrm{NO}_{x}$. However, the additional energy use involved, included in the cost, leads to additional emissions of 4,000 tons of $\mathrm{CO}_{2}$. What to do? What is best? Along comes a convincing environmentalist: "Let's be environmentally effective! Let's do them all: One for the climate and the five for the acid rain." And so it is decided. All is done and $€ 2$ million is spent per year. As to the environmental impact of this decision, $\mathrm{CO}_{2}$ emissions remain the same, as the plusses and minuses exactly balance. The $\mathrm{NO}_{x}$ emission reductions balance to zero as well. So there is no net environmental improvement at all. Quite a large sum of money is spent to no avail in terms of climate and acidification, and the activities definitely will have other negative environmental impacts, like on resource depletion and toxicity. Would either of the options alone have been better? Which one? How to answer that question? Based on one's personal preferences or based on broader societal considerations? Would these choices have contributed to decoupling of economic growth from environmental impact? Would these decisions have been sustainable? Some overall measure on environmental performance then is needed, 
requiring weighting, as operational evaluation, and some way of balancing against cost.

More real situations are more complex. The example of only two technologies with only two emissions and two impact categories involved is artificial and non-existent. In real life, myriads of decisions are made, each with many options and each with thousands of different environmental interventions involved, ranging from resource extractions and different types of land use to emissions of large number of different substances, radiation and noise. Real situations always are complex, without an easy dominance analysis leading to clear choices.

Weighting is unavoidable, better explicit than implicit. In any specific choice, virtually all environmental impacts are involved, as are economic value creation and its negative counterpart costs. We cannot avoid the weighing between them. We may choose to make the choice implicitly. We then close our eyes for the nasty interrelations and the partly disappointing consequences involved. Explicit treatment will require some form of weighting, if only to get some overview. Also, we not only may want to make wise decisions on a product system, but also want to know if we have done well at a more aggregate level, as a firm, or as society, and if future developments go in the right direction. Did we take the right decisions in the past? How do we compare to others? Dow we have the right policies in place? Also, at this aggregate level, we need some overview "how we did environmentally," requiring aggregation which by necessity is based on weighting.

Weighting is not easy. The different environmental impact categories give insight in effect mechanisms, with reasonable validity, but also with discussion, as for example on the exact mechanisms of climate change. These environmental impacts are very diverse, with relations towards endpoints highly disputable as to mechanisms and completeness, and conditions for them to occur. To complicate matters, many environmental stressors work out with delays; they may last for different periods (extinction is forever); and they may interrelate. Fine dust has health effects ranging from simultaneous to life time, climate changing emissions have different time horizons, with climate change being influenced for up to centuries and millennia. Getting an overall view of "how we are doing" requires reconciling these different frames, in one evaluation framework.

\section{Paper outline}

We first surveyed the field of weighting methods, developing a framework for typifying options. Next, we chose three basic approaches, each most consistent in itself, and filled with a number of operational methods. These three approaches are developed operationally for our purpose here. We expanded their applicability to the broadest and most generally specified level, based on the ILCD Handbook on LCIA (EC-JRC European Commission-Joint Research Centre 2011) as the reference for characterisation in LCA. To show how they work out we applied them to a time series of emission data for the EU. This data set has been chosen as reflecting the broadest set of environmental interventions for aggregate performance of society now available. Finally, the question is how to deal with these three different weighting options? At an aggregate level of one country, they lead to very similar outcomes. For different countries and sectors the outcomes might be more disparate. And for application at a micro level of specific technologies and policies, they will certainly differ in their outcomes. As they have different strengths and weaknesses a mixed approach is developed, where the methods in the three approaches are combined into one, as a metaweighting method. The result is available as a spreadsheet, applicable to a broad set of environmental interventions. It can also be applied in a disaggregated way, showing the relative importance of specific environmental interventions and of specific impact categories. The easy choice of emphasis between the weighting methods also allows for an active sensitivity analysis.

\section{Framework}

The framework to describe the different weighting approaches builds on two main issues: (1) the place in the cause-effect chain where weighting is applied and (2) the type of values and preferences involved in weighting and the basis for measuring these. The approaches for impact assessment and weighting across impact categories differ in the extent to which the causal effect chains are modelled in characterisation, hence differ where the subsequent weighting starts to be applied. Effect levels may be distinguished in midpoint and endpoint effects, i.e., in terms of Drivers - Pressures - State Impact - Response (DPSIR) (see the ETDS of the European Environment Agency) respectively as State and Damage indicators. The weighing applied at midpoint outcomes implies an implicit judgement on further empirical effects.

As to the actual weighting across impact categories, either defined at midpoint or endpoint level, weighting sets can be classified into different families depending on how the weighting is performed and on which basis. Figure 1 presents a taxonomy of weighting approaches that specifies main types of methods used to arrive at a single score. Some methods are not really weighting methods, like single item methods which pick out "the" main effect type, as in the footprint. Next, there are value-based and preference-based methods. Value-based judgements focus on one aspect corresponding to one value. Each value constitutes a reason why one option is preferred to another. These considerations are of a mainly qualitative nature. With several values being relevant, lexicographic ordering of values then may form the basis for ordering options. One value domain then is more important than all other values together, without any trade-offs. In the environmental domain, this seems highly improbable. Hence, only in very exceptional situations may some alternative be dominant (or dominated) in all value domains. Value-based ordering will normally not lead to a relevant resolution when comparing closely related options. 
Fig. 1 Taxonomy of weighting approaches. 1. Willingness-topay, marginal, for emission/ damage reduction or prevention in current (or reference) emission situation. 2. Willingnessto-pay, marginal, for emission/ damage reduction in hypothetical optimum situation. 3. Marginal cost to reach stated emission (reduction) target. Idem for higher reduction target 3'. 4. Currently induced highest marginal cost of emission reduction. 5. Current private marginal expenditure for emission/damage prevention. 6 . Budget limit for marginal willingness-to-pay for damage reduction, current income, current situation (as the area under the red curve)

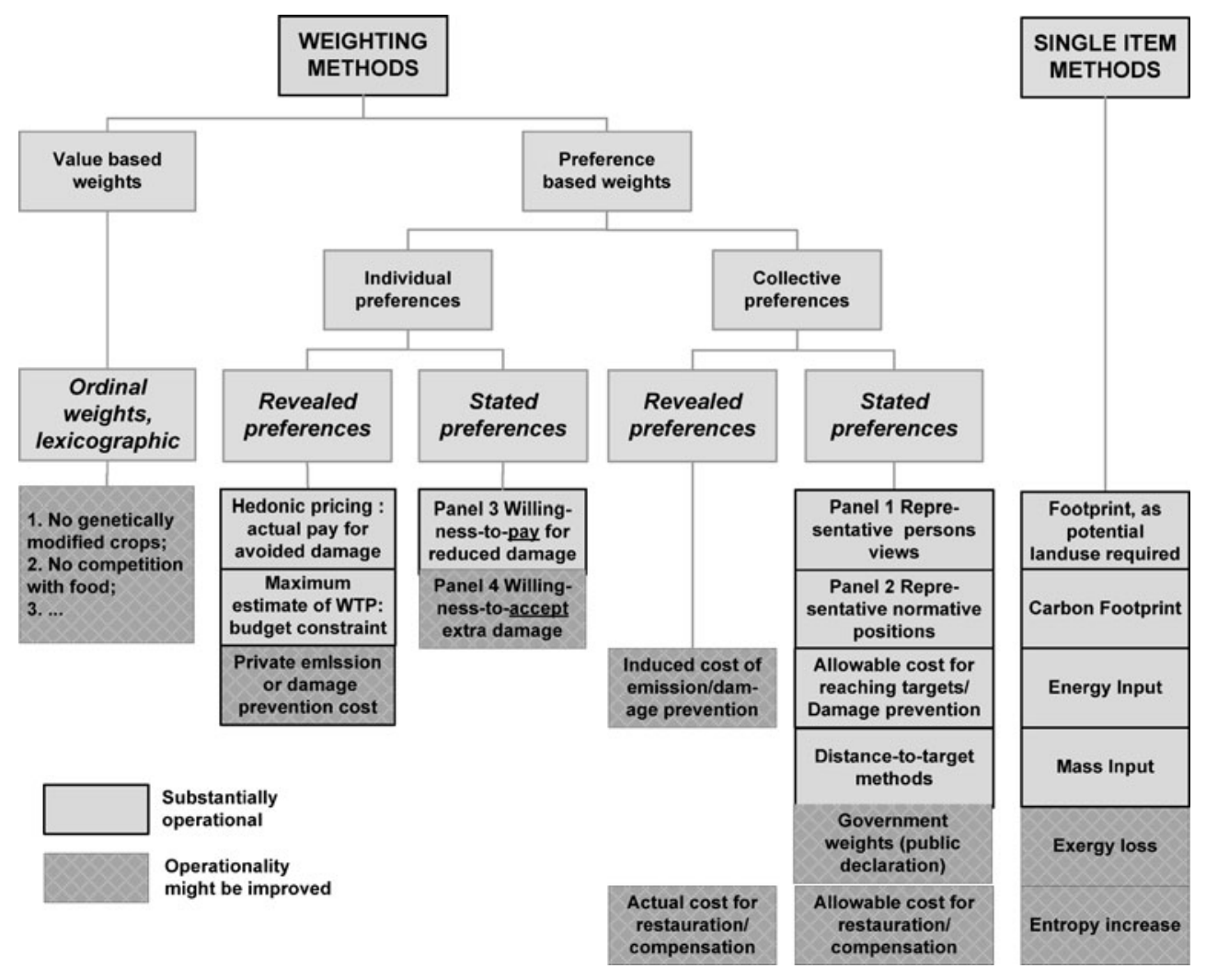

an eloquent survey on the limitations of utility-based monetisation of external effects.

The final distinction in Fig. 1 pertains to measurement of preferences, either through explicit statements, as stated preferences, or derived from decisions actually done, as revealed preferences. Revealed preferences are derived from how decisions are actually made, inferring the preferences from the decisions and their assumed, modelled consequences. However, revealed preferences can reflect choices of the past only and are difficult to apply in situations where very many characteristics are relevant for choices. Therefore, they cannot guide new policies, for example, based on new insights in the seriousness of the effects of climate change. Direct statements on preferences are an expression on what is to be preferred over what, i.e., which set of environmental effects is considered to be more important over another full set. How such statements are collected is very open. A much used method is asking persons or public bodies to rank alternatives. This method is flexible but prone to manipulation and inconsistency. However, for the judgement of future impacts of emissions the weighting sets based on direct statements seem to be the most appropriate category of weighting approaches for the weighting across environmental impact categories. Some methods give a score based on dimensionless weights, and some are expressed in monetary terms. As the monetised scores refer to effects not reflected in market prices they may be referred to as monetised external costs, also named 
shadow prices. If priced accordingly in real markets, the external effects would be internalised. There are several methods which lead to monetised values for the effects considered. Also, the non-monetised weights may easily be converted into monetised ones if one of the effects in the weighting scheme is given a monetised reference. All other effects then follow suit. However, some caution is required here, as for example the choice of the reference will determine the outcome.

Figure 2 presents several monetizing methods and their possible levels of damages or cost. The private preferencebased method as willingness-to-pay is most fitting in the economic valuation approach. The marginal valuation in principle is relative to a reference situation. With lower emission levels, the value of the damages resulting will be lower in principle, the curve showing a demand for emission reduction. Reversing the legal status, as in asking the willingness to accept damages, will lead to differing results, for example because one cannot pay more than one's income to prevent damage, but may easily require a much larger sum to accept the damage occurring.

The curves as sketched are not empirically available but reflect general notions as to the form of supply and demand relations. The equilibrium point 2 is what ideally is specified, at a certain point in time. However, this point, to be specified dynamically, is not available empirically. The core issue to note here is that all other methods may deviate substantially from this "ideal" damage valuation method. Current policy-induced emission reduction cost may be an order of magnitude lower, while cost currently incurred for private considerations may be an order of magnitude lower again. The cost of reaching targets, often used as a proxy for missing data on willingness-to-pay, may be substantially

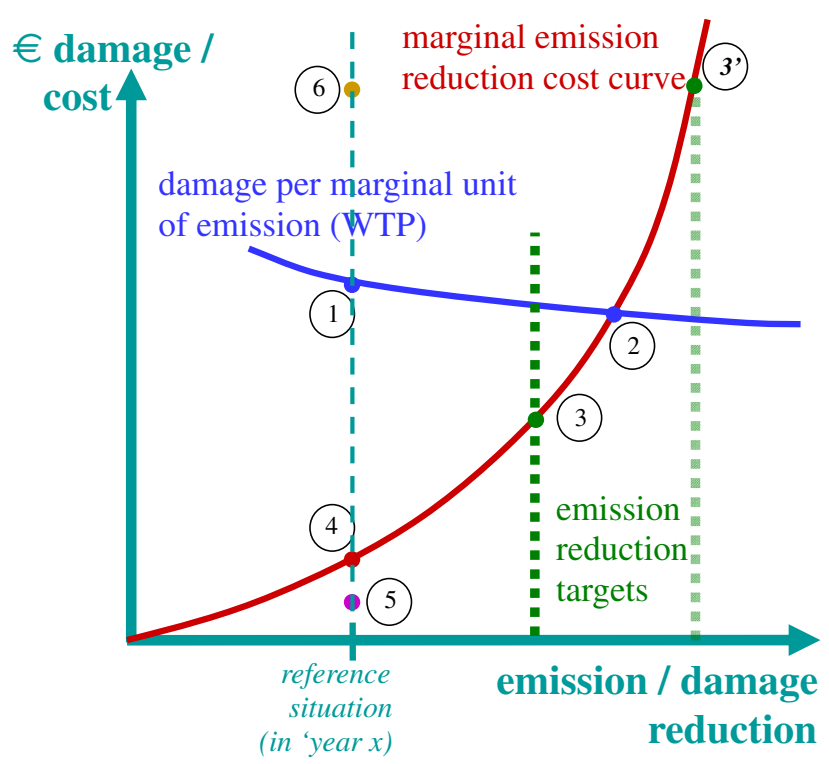

Fig. 2 Monetary values for selected methods lower, or substantially higher than the ideal willingness-topay or proxies to that. For higher targets the cost usually surge to orders of magnitude above the blue line. Minimum and maximum scores hence may easily differ more than two orders of magnitude. Mixing monetising methods therefore is unallowable if interpretable results are to be produced, with a validity which can at least be discussed. The precision in economic evaluation allows for this analysis. In more loose approaches to evaluation, such issues do not come to the fore; they remain hidden.

\section{Operational methods considered: survey}

As a first step towards recommendation of a weighting approach for measuring the EU overall environmental impact several operational weighting methods have been surveyed (Huppes and van Oers 2011a,b; original 2009). Table 1 gives an overview of the quantified operational weighting methods that have been analysed, with the ones used in the meta-method in shown in italics. The taxonomy (see Fig. 1) is used for classifying relevant approaches. Furthermore, at a more practical level several additional criteria apply, such as: weighting procedure (e.g., distanceto-target [DTT], panel); modelling of cause-effect chain; environmental interventions covered; environmental impacts covered, etc. We always use the ILCD Handbook methods for life cycle impact assessment as a reference.

The overall conclusion of the survey is that the methods classified under "collective revealed preferences" are not based on the evaluation of different expected effects and thus lack an explicit weighting step across impact categories. These methods use distance-to-target for weights, or effectively also other measures, like prevention cost or some green taxes, to specify an overall score. For some methods the hybrid nature made it impossible to classify them in the framework, like the CIRAIG method by Soares et al. (2006). Similarly, domain specific weighting methods could not be used, like the BEPAS method by Zhang et al. (2006). The method of weighting not only may be a mixed one but often it just is not clear conceptually, building on several other previous studies. Some weighting methods might better not be called by that name. In a distance-to-target method, the "targets" may all be weighted "equally" and so no reasoned weighting across impact categories is applied, only a quite random and scale dependent one-one-weighting set. As to the methods classified under "single item methods," these technically are no weighting methods because they refer only to one impact category. One might interpret them as weighting methods placing a fully dominant weight at the issue chosen, like the carbon footprint leaving out all noncarbon effects. This leaves the methods based on stated preferences as basis for further development of a weighting 
Table 1 Classification of quantified operational weighting methods

\begin{tabular}{|c|c|c|c|c|c|}
\hline \multirow[t]{3}{*}{ Modelling level } & \multicolumn{5}{|l|}{ Weighting type } \\
\hline & \multirow{2}{*}{$\begin{array}{l}\text { Collective stated } \\
\text { preferences } \\
\text { Non-monetised } \\
\text { Panel } 1\end{array}$} & \multicolumn{2}{|l|}{ Collective revealed preferences } & \multirow{2}{*}{$\begin{array}{l}\text { Individual stated } \\
\text { preferences } \\
\text { Monetised } \\
\text { WTP Panel } 3\end{array}$} & \multirow[t]{2}{*}{ Single item methods } \\
\hline & & $\begin{array}{l}\text { Non-monetised } \\
\text { DTT }\end{array}$ & $\begin{array}{l}\text { Monetised } \\
\text { Damage prevention } \\
\text { cost }\end{array}$ & & \\
\hline Interventions & $\begin{array}{l}\text { Ecotax }(98 / 02 / 06) \\
\quad \text { (Finnveden et al. } \\
\text { 2006; Eldh 2003) }\end{array}$ & $\begin{array}{l}\text { Ecopoints (Frischknecht et al. } \\
\text { 2008) }\end{array}$ & & & $\begin{array}{l}\text { Ecological Footprint (Wackernagel } \\
\text { et al. 2005) }\end{array}$ \\
\hline \multirow[t]{2}{*}{ Midpoint } & $\begin{array}{l}\text { BEES and EPA (Lippiatt } \\
\text { 2007) }\end{array}$ & $\begin{array}{l}\text { EDIP (Wenzel et al. 1997; } \\
\text { Hauschild and Wenzel } \\
\text { 1998) }\end{array}$ & & $\begin{array}{l}\text { Ecovalue08 (Ahlroth and } \\
\text { Finnveden 2009) }\end{array}$ & $\begin{array}{l}\text { Cumulative. Fossil Energy } \\
\text { Demand, CED (Huijbregts } \\
\text { et al. 2006) }\end{array}$ \\
\hline & Nogepa (Huppes et al. 2007) & & & & \\
\hline \multirow[t]{4}{*}{ Endpoint } & & & $\begin{array}{l}\text { ReCiPe-shadow prices } \\
\text { (de Bruyn et al. 2010) }\end{array}$ & $\begin{array}{l}\text { ReCiPe-damage cost } \\
\text { (Heijungs 2008) }\end{array}$ & \\
\hline & $\begin{array}{l}\text { Ecoindicator99 (Goedkoop } \\
\text { and Spriensma 2000) }\end{array}$ & & $\begin{array}{l}\text { Eco-costs/Value Ratio } \\
\text { (Vogtländer et al. 2009) }\end{array}$ & LIME (Itsubo et al. 2004). & \\
\hline & & & & EPS (Steen 1999a,b) & \\
\hline & & & & $\begin{array}{l}\text { Budget constrained WTP } \\
\text { (Weidema 2009) }\end{array}$ & \\
\hline \multirow[t]{2}{*}{$\begin{array}{l}\text { Integrated modelling } \\
\text { and weighting }\end{array}$} & & & & $\begin{array}{l}\text { NEEDS (Preiss and Klotz } \\
\text { 2008) }\end{array}$ & $\begin{array}{l}\text { Damage cost GHG emissions (Tol } \\
\text { 2008; Stern 2007) }\end{array}$ \\
\hline & & & & & $\begin{array}{l}\text { Damage cost resource extractions } \\
\text { (Weitzman 1999) }\end{array}$ \\
\hline
\end{tabular}

tool, be they individual utility-based or having some collective preference or value element. We added some single issue methods which may complement other conceptually similar methods, as for climate change and resource depletion.

However, there is no well-defined total set of methods from which to make a choice. In the LCA domain there are earlier survey studies, as by Finnveden (1999) and Ahlroth (2009). To cite Finnveden: "The major conclusion is that none of the presently available methods can be recommended for use as an LCA valuation (weighting) method today. This is mainly because they either suffer from significant data gaps, include inconsistencies, lack justification of major assumptions, or because they are not valuation methods at all." In the economics domain, there is a good survey on the panel studies that have been used as a basis for monetization by Turner et al. (2004). For the domain of climate policy only, Tol (2008) has given a survey of outcomes of a large set of studies, with nearly the same material as used in the NEEDS study (Tol 2006). Summarizing the situation is sobering. There is not one clear set of weighting methods to choose from; the criteria for selection of relevant ones from this hypothetical set are soft; and as indicated here, applying these criteria often is not practically possible due to the mixed and unknown nature of methods.

With all these considerations in mind, a selection of methods has been made from a not-encompassing survey (see Table 1). Next, a choice of operational methods was made to use in the meta-weighting tool as has been developed. For a more detailed analysis for reasons of inclusion, see Huppes and van Oers (2011a), where 14 methods have been described in more detail. We would have liked to include only clear single-method stated preference approaches, with broad applicability. But that would have excluded almost all of the available ones. So, a slightly dirty choice was unavoidable.

\section{Methods specified: three basic approaches}

\subsection{Modelling and evaluation}

The remaining methods can be typified into three categories, based on the modelling characteristics and the method of weighting, all giving results in terms of a judgement on the seriousness of expected effects involved.

(1) Midpoint modelling and evaluation: BEES, EPA (Lippiatt 2007), NOGEPA (Huppes et al. 2007). Midpoint weighting methods stop modelling at the midpoint level and implicitly leave the assessment of further effects to the subjective judgment of panel members in the weighting procedure. The members then should be knowledgeable and authoritative.

(2) Endpoint modelling and evaluation: Ecoindicator99 (Goedkoop and Spriensma 2000), LIME (Itsubo et al. 2004), ReCiPe damage (Heijungs 2008). In the endpoint weighting methods, there is a formalized modelling of the causal chains from midpoint to endpoint. Subsequently, the weighting is based on endpoint 
effects. The valuation of endpoints can be based on panels linked to this specific approach, or they may use the more general panels as being used by economists to quantify the value of externalities

(3) Integrated modelling and evaluation: NEEDS (Preiss and Klotz 2008) + Weitzman (1999). Outside the domain of the ILCD, integrated models have evolved, linking environmental interventions to damages of endpoints and valuation of damages using damage cost. These models mostly have been developed in relation to economic valuation, as in models for climate change and for toxic effects on human populations. The NEEDS method (Preiss and Klotz 2008) lacks the valuation of the depletion of abiotic resources and therefore is supplemented with the valuation based on the conceptually similar Weitzman (1999) data. The panels used for economic valuation ideally are representative of the general population. In the integrated modelling the intermediate effects on midpoint and endpoint level are modelled in a combined way, but not explicitly presented, so mutual consistency cannot be established.

All methods are based on the aggregation of interventions into effects based on formalized modelling and a subsequent subjective weighting across these effects. Figure 3 shows the overall procedure of impact assessment using characterisation and weighting across impact categories.

The results of this characterisation, the impact scores, are still hard to interpret. The scores for the different impact categories are expressed in different units. To facilitate the interpretation in LCA often a normalization procedure is used. If the environmental impact assessment includes a weighting across impact categories into one overall environmental impact score the normalization is a necessary step in case panel weighting is used (e.g., BEES, NOGEPA, Ecoindicator99, LIME [dimensionless set]). In case the weighting is based on monetized valuation of damages, the normalization (e.g., ReCiPe damage cost, NEEDS) is not necessary but may be applied in order to arrive at similar outcomes.

So, after normalization for each impact category the normalized score of the case study is given. This normalized score expresses the relative contribution of the case study to the impact score based on the interventions of total society, here the total world economy. So for, each of the impact categories the result is expressed as a fraction of contribution to the total world problem. For this purpose, information is needed on the total of extractions and emissions in the world. These reference interventions are taken from a recent normalization study (Wegener Sleeswijk et al. 2008). The reference situation here refers to the extractions and emissions by the world in the year 2000 .

\subsection{Methods quantified}

The factors necessary for the impact assessment of the overall environmental impact of the EU27 interventions are reported in a spreadsheet that accompanies this article. The spreadsheet contains characterisation factors (ILCD
Fig. 3 Overall set up of impact assessment for the selected approaches

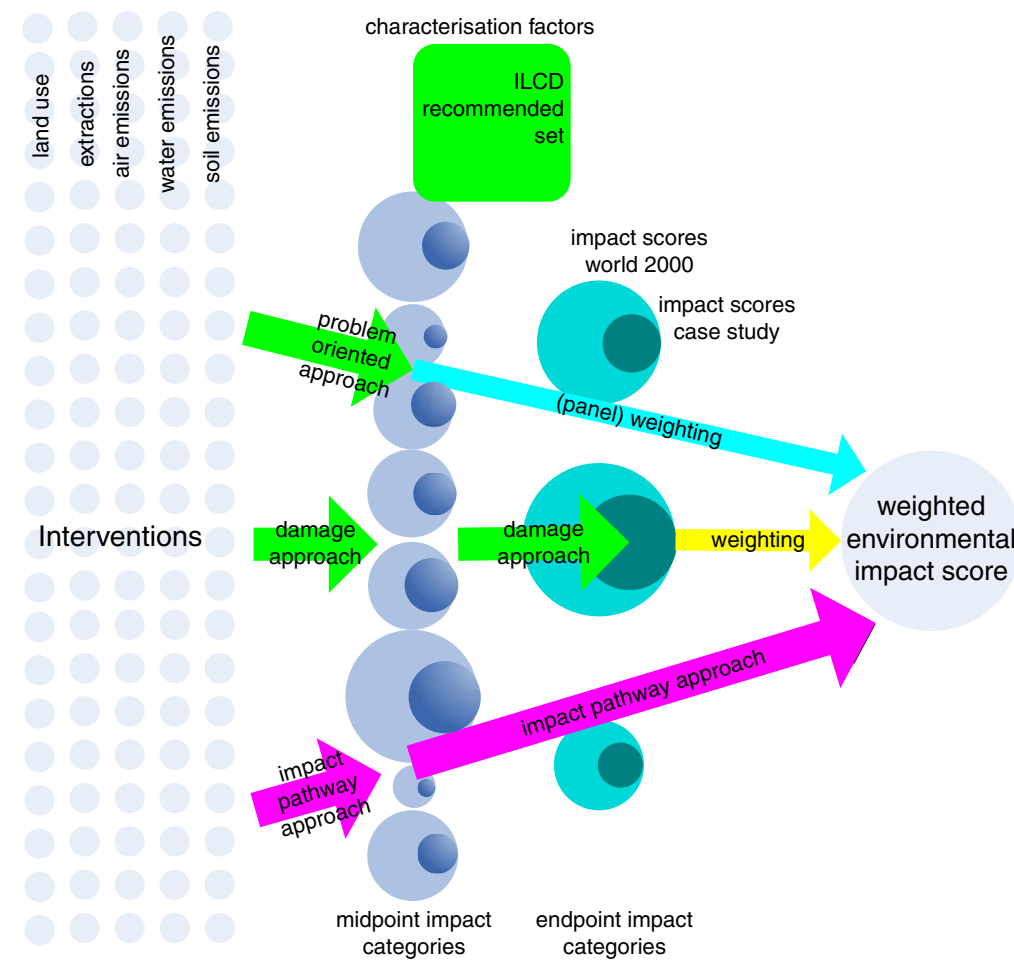

weighting factors

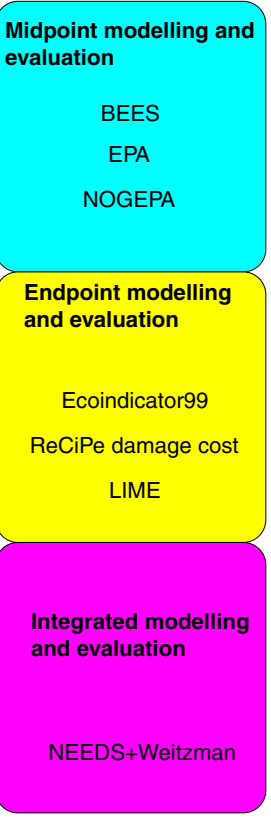


Handbook on LCIA; EC-JRC European Commission-Joint Research Centre 2011), normalisation factors (Wegener Sleeswijk et al. 2008), and weighting factors (Table 2) and can be downloaded from CML (see Appendix 1). Table 2 shows a summary of the weighting factors based on different weighting methods. The weighting factors of the original weighting sets have been adapted to align with the impact categories as defined in the recent ILCD Handbook on LCIA (EC-JRC European Commission-Joint Research Centre 2011). The selected weighting methods all have operational weighting factors. The midpoint weighting factors needed limited data transfer in order to comply with the ILCD recommended characterisation factors (Huppes and van Oers 2011b). The recently developed set of characterisation factors seemed to be not yet fully consistent in the modelling of midpoint and endpoint factors and have been adapted where possible.

The integrated modelling and weighting according to NEEDS is only available for a limited number of emissions to air. Estimation of factors for missing emissions of NEEDS is based on data transfer using the ILCD characterisation factors as extrapolation factors. For details, see Huppes and van Oers (2011b). The effect of equalized applicability is a convergence between NEEDS and the midpoint-based weighting methods. The degree of convergence of course depends on the case. If the case is dominated by emissions already present in the unadjusted NEEDS, there is no convergence induced, and vice versa. NEEDS factors also lack the valuation of the depletion of resources, one full impact category. For this reason, the NEEDS factors are supplemented with Weitzman's economic approach to depletion (1999). In NEEDS the marginal damage cost for $\mathrm{CO}_{2}$ emissions is set at $€ 6 /$ ton $\mathrm{CO}_{2}$ (no equity weighting, $3 \%$ discount rate; see Preiss and Klotz 2008). These original damage cost for emissions of greenhouse gases (GHGs) in NEEDS have been raised with a factor 10, to allow for effects not covered in NEEDS, including the low-chance, high-impact effects (see Weitzman 2009). These figures correspond reasonably with the figures as used by Stern (2007). The NEEDS factors are only available on the level of substance emissions. For an overview of the original NEEDS factors and extrapolated and adapted values please refer to the spreadsheet. Normalisation factors are based on the total of interventions (emissions and extractions) in the world in 2000, taken from Wegener Sleeswijk et al. (2008).

\section{Three basic approaches combined}

The three impact evaluation procedures are conceptually different. They model the intervention-effect chain but are different in the level to which the effect is modelled, i.e., midpoint "state" indicators, endpoint "damage" indicators or "damage cost" indicators. The midpoint and endpoint

Table 2 Adapted weighting factors based on different weighting methods

\begin{tabular}{|c|c|c|c|c|c|c|c|c|}
\hline \multirow{2}{*}{$\begin{array}{l}\text { Area of } \\
\text { Protection }\end{array}$} & \multirow{2}{*}{$\begin{array}{l}\text { Impact category on } \\
\text { midpoint level }\end{array}$} & \multicolumn{7}{|l|}{ Weighting method } \\
\hline & & $\begin{array}{l}\text { EPA Science Adv. } \\
\text { Board } \\
\%\end{array}$ & $\begin{array}{l}\text { BEES Stake- } \\
\text { holder Panel } \\
\%\end{array}$ & $\begin{array}{l}\text { NOGEPA with } \\
\text { add. factors } \\
\%\end{array}$ & $\begin{array}{l}\text { Lime } \\
\%\end{array}$ & $\begin{array}{l}\text { Eco indica-tor99 } \\
\%\end{array}$ & $\begin{array}{l}\text { ReCiPe dam. } \\
\text { cost } \\
\$ / \text { unit dam. }\end{array}$ & $\begin{array}{l}\text { NEEDS dam. cost } \\
\text { (some examples) } \\
€ / \mathrm{kg} \text { em. }\end{array}$ \\
\hline \multirow[t]{7}{*}{ Human Health } & Climate change & 16 & 29 & 25 & 33 & 30 & 60,000 & $0.06\left(\mathrm{CO}_{2}\right)$ \\
\hline & Ozone depletion & 5 & 2 & 4 & & & & \\
\hline & Human health cancer. & 7 & 8 & 5 & & & & 3.7E7 (dioxin) \\
\hline & Human health non-cancer & 4 & 5 & 3 & & & & 278 (lead) \\
\hline & $\begin{array}{l}\text { Particulate matter/respiratory } \\
\text { inorganics }\end{array}$ & 6 & 9 & 5 & & & & $6.07\left(\mathrm{SO}_{2}\right)$ \\
\hline & $\begin{array}{l}\text { Ionising radiation, human } \\
\text { health }\end{array}$ & 6 & 2 & 3 & & & & $0.0014(\mathrm{C} 14)$ \\
\hline & $\begin{array}{l}\text { Photochemical ozone } \\
\text { formation }\end{array}$ & 6 & 4 & 6 & & & & \\
\hline \multirow[t]{5}{*}{ Natural environment } & climate change & $\mathrm{N} / \mathrm{A}^{\mathrm{a}}$ & $\mathrm{N} / \mathrm{A}^{\mathrm{s}}$ & $\mathrm{N} / \mathrm{A}^{\mathrm{a}}$ & 52 & 40 & $1.75 \mathrm{E} 11$ & \\
\hline & Acidification & 5 & 3 & 5 & & & & \\
\hline & Eutrophication & 5 & 6 & 10 & & & & \\
\hline & Fresh water ecotoxicity & 11 & 7 & 15 & & & & \\
\hline & $\begin{array}{l}\text { Ionising radiation, } \\
\text { ecosystems }\end{array}$ & 6 & 2 & 3 & & & & \\
\hline \multirow[t]{3}{*}{ Resources } & Abiotic resource depletion & 5 & 10 & 6 & 14 & 30 & 1 & 0.00103 (oil) \\
\hline & Water intake & 3 & 8 & 4 & & & & \\
\hline & Land use & 16 & 6 & 8 & & & & \\
\hline
\end{tabular}

${ }^{a}$ The ILCD recommended characterisation on midpoint level does not distinguish between climate change impacts on human health and ecosystem health 
modelling and weighting build on the characterization according to the ILCD recommended set of characterisation factors. The integrated modelling and weighting methods according to NEEDS builds, implicitly, on detailed distribution, fate and effect models. These models differ from the models recommended in the ILCD Handbook. However, their status outside the LCA community is well established, also in the policy domain. Therefore, we include them as one of the three approaches to weighting in the combined weighting method.

All methods suffer from inconsistencies in modelling of the impacts for different impact categories. For example, the modelling of the time scale, spatial scale, treatment of background concentrations and multimedia distribution is different for different impact categories. These differences are most apparent for the midpoint effects which are defined for different time and spatial scale levels but just are hidden from view in the other methods. Correction of these differences in the weighting makes this procedure even fuzzier. However, the midpoint to endpoint modelling should also deal with these differences. This makes the endpoint modelling even more uncertain.

The three groups of methods each have their relative strengths and weaknesses, on which different views are very well possible (Huppes and van Oers 2011a). Midpoint approaches have a clear modelling basis with mutually inconsistent elements and they rely on extensive subjective estimates in the combined further-modelling- and weighting step. Endpoint models have a weak modelling step after the midpoint and then are conceptually similar to the valuation step in the economics oriented integrated modelling and weighting. The underlying specification is poor, however, compared to the integrated modelling approach. The integrated modelling approach has some strong points in modelling, as in climate modelling and human toxicity, but is weak in its further modelling. The valuation step of this approach is best specified, based on thoroughly tried but not undisputed methods.

As to the right method, it seems that neither is perfect, nor will one method be generally accepted.

The basic choice on a framework for evaluation, the internal inconsistencies in underlying modelling, and the rather haphazard nature of many choices involved all indicate that the choice for one method is not the right direction to go now, or in the foreseeable future. Just adding another weighting set, an improved one, would hardly improve the overall situation. A major effort on environmental modelling is due, to make methods more consistent and then also more similar. More precise links to evaluation then can be established as well.

For now, we have chosen a most open solution, reckoning with the different approaches and methods, but not leaving all choices open. The seven most broadly applicable and consistent methods have not just been chosen. Each of them has been made as consistent as possible and has been expanded as much as possible so as to apply to the same broad set of environmental interventions as present in actual situations of environmental evaluation and choice. The NEEDS approach also has been expanded so as to cover resource depletion. Though fundamentally different in structure, the three approaches thus are directly comparable in their results, linking environmental interventions to weighted results. Also, by using the same methods for establishing normalisation data, they can be adapted easily to new sets of data becoming available and can easily be used for scenario analysis using possible future sets of total environmental interventions.

Improving the modelling behind the evaluation is possible, leading to adapted characterisation factors. Adding new, different, characterisation factors would require new weighting procedures.

A special question is how to deal with missing intervention data, fully for one impact category. Its weight will then be zero, automatically for its contribution to midpoint scores, and implicitly also for end point methods. It seems no special adaptation for such a situation is required. It is clearly visible in the results. Some more detailed analysis might due here.

To allow for easy application, and for easy adaptation regarding new developments, the weighting procedure has been implemented in a freely available spreadsheet (see Appendix 1). The user may use the default meta-weights but may easily adapt the contribution of the different weighting sets to the combined result. By setting one method at $100 \%$, the weighting by only that method results. Table 3 shows an exemplary setting of the selection of the weighting methods, as a default. It is the base line in the spreadsheet, quite arbitrarily chosen now. The low scores for the endpoint methods are based on their lack of transparency, their not well-developed underlying models and their limited correspondence to ILCD. Future developments in

Table 3 Weighting of methods in the meta-weighting tool

\begin{tabular}{lll}
\hline Type of weighting approach & $\begin{array}{l}\text { Operational } \\
\text { weighting sets }\end{array}$ & $\begin{array}{l}\text { Meta-weighting } \\
\text { set }\end{array}$ \\
\hline $\begin{array}{ll}\text { Midpoint modelling and } \\
\text { evaluation }\end{array}$ & BEES & 25 \\
& EPA & 25 \\
& NOGEPA & 25 \\
Endpoint modelling and & Ecoindicator99 & 2 \\
evaluation & LIME & 2 \\
& ReCiPe damage & 1 \\
& value & 20 \\
Integrated modelling and & NEEDS+Weitzman & 100 \\
evaluation & & \\
\hline
\end{tabular}


characterization models and weighting values might lead to further convergence of the methods and approaches, but also to divergence especially where treatment of time frames differs.

\section{Exemplary application to country level time series}

As an illustration of the use of the weighting factors for a decoupling indicator, the impact assessment has been applied to a broad data set with time series for the EU. Ideally, such a data set should encompass a broad set of impact categories related to a broad set of environmental interventions monitored over a long period of time. However, many empirical time series of inventory data, like NAMEA, are poor concerning the time span they cover and the emissions they take into account. For this reason, the time series of inventory data are constructed data. The outcomes, therefore, are exemplary, giving a rough indication only. Direct times series data should be produced in due time.

The constructed inventory data are based on materials use for which data are more readily available combined with LCA type of process data to deliver a rich set of interventions, as a time series. The result is the Environmentally weighted Materials Consumption indicator (EMC). The EMC was drafted as an option for the overall economicenvironmental decoupling indicator to support the EU
Thematic Strategy on Natural Resources (Van der Voet et al. 2005, 2009).

Figure 4 depicts the scores for the midpoint impact categories. These show quite some variation in their development, hence requiring weighting for arriving at an overall view regarding decoupling. Figure 5 gives the weighted score per method and for the combined method, the metaweighting score in dark blue. Most striking is the fact that methods from such diverse evaluation backgrounds and with such different modelling involved still converge so much. Is there an underlying convergence mechanism which leads to this result? One such a mechanism might be the tendency for researchers to leave out outliers. In the process of combining different studies, so well described by Turner et al. 2004), this may well lead to convergence, especially if enough iterations follow.

Table 4 shows the relative contribution of substancecompartment-emissions to the total environmental impact score of the EU28 in the year 2000. The results are based on the separate different weighting sets. This top 20 of substance-compartment-emissions contribute for about $90 \%$ to the total environmental impact score. The general picture of most dominant emissions is more or less the same for all weighting methods.

Most dominant emissions are, on average, carbon dioxide, dioxin, carbon-14, hydrogen-3, zinc, mercury and nitrogen dioxide. Also, other GHG emissions, like methane and di-nitrogen
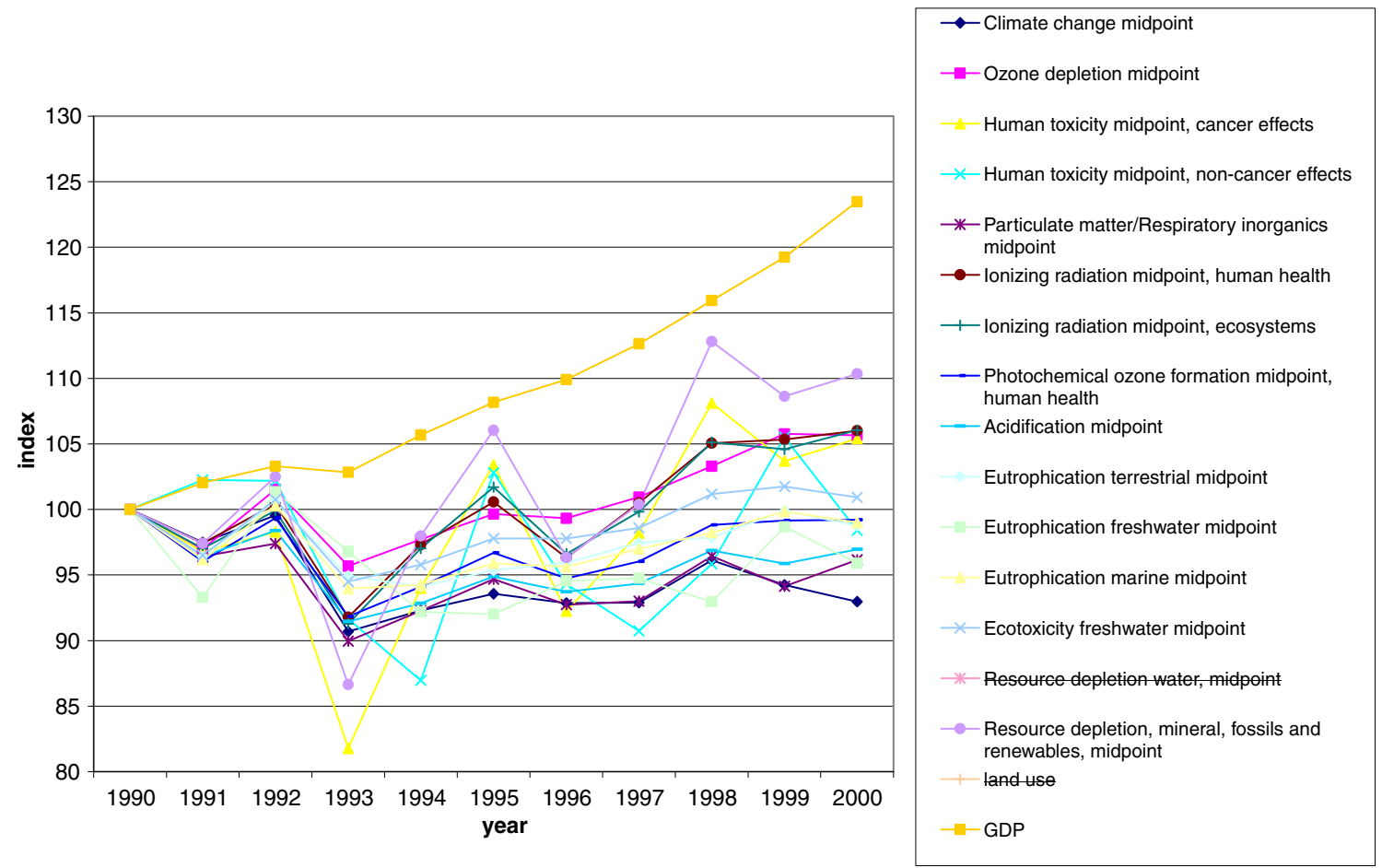

Fig. 4 GDP and normalised impact scores per midpoint impact category for the EU15 in the year 1990-2000. (Intervention profiles for the years are based on EMC (van der Voet et al. 2005, 2009); strike- through impact categories are not yet available in the latest version of ILCD characterisation factors) 

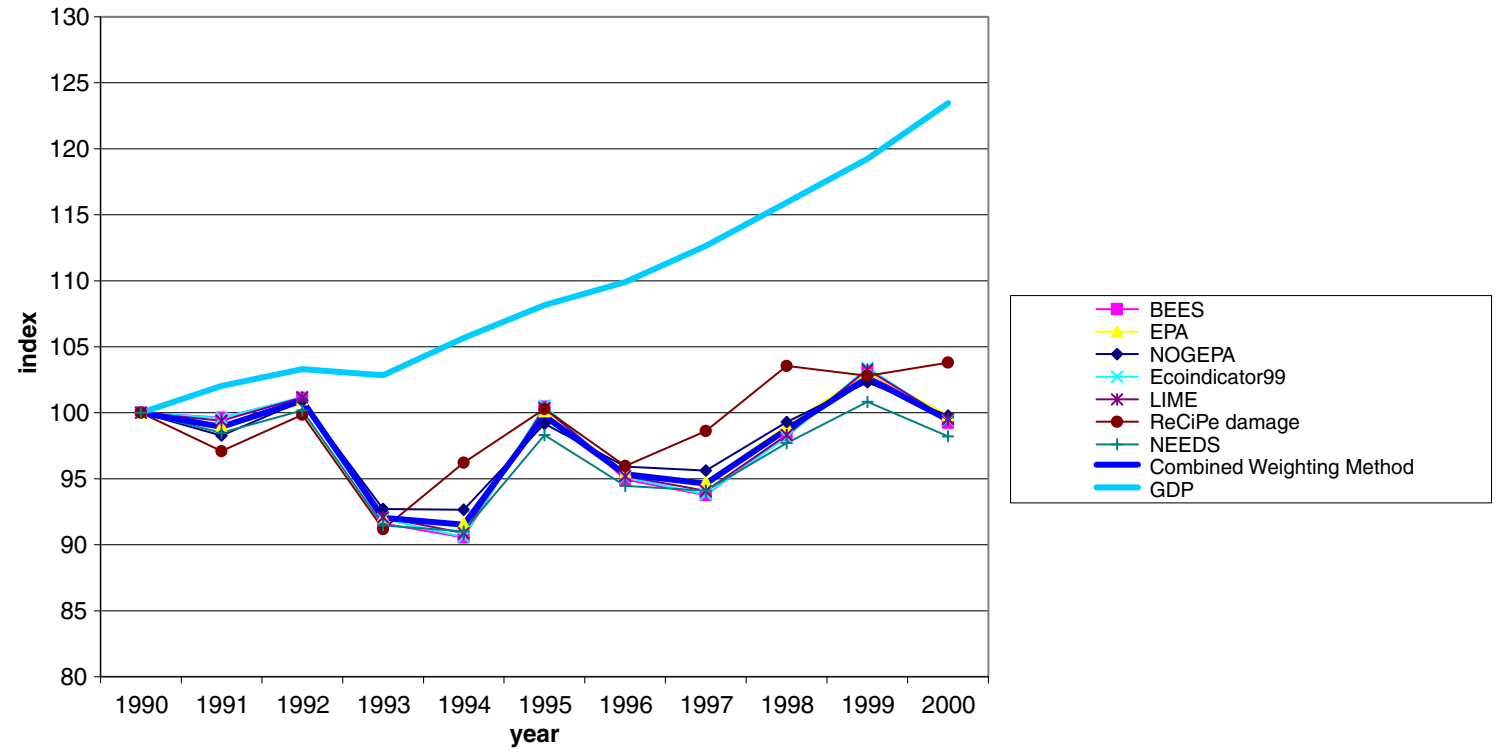

Fig. 5 GDP and environmental impact scores for the EU15 in the years 1990-2000. (Intervention profiles are based on EMC; Van der Voet et al. 2005, 2009)

oxide, bulk emissions like sulfur dioxide, NMVOCs and PM10 are part of the top 20 . The remaining of the top 20 mainly consists of emissions of pesticides to the soil.
This list of top 20 emissions is, more or less, in line with general expectations, but there is quite some discussion possible on why some scores are so high, and others so

Table 4 Contribution of substance intervention/compartment to the weighted impact score of EU28 in 2000 (\%)

\begin{tabular}{|c|c|c|c|c|c|c|c|c|}
\hline \multirow[b]{2}{*}{ Substance } & \multirow[b]{2}{*}{ Compartment } & \multicolumn{3}{|c|}{$\begin{array}{l}\text { Midpoint modelling (ILCD) } \\
\text { and weighting }\end{array}$} & \multicolumn{3}{|c|}{$\begin{array}{l}\text { Endpoint modelling (ILCD) and } \\
\text { weighting }\end{array}$} & \multirow{2}{*}{$\begin{array}{l}\text { Integrated modelling and } \\
\text { valuation }\end{array}$} \\
\hline & & BEES & EPA & NOGEPA & Ecoindicator99 & LIME & ReCiPe damage & \\
\hline Carbon dioxide & Air & 22 & 11 & 19 & 9 & 9 & 16 & 37 \\
\hline Carbon-14 & Air & 5 & 16 & 9 & 16 & 16 & 10 & \\
\hline Mercury & Air & 12 & 9 & 7 & 9 & 9 & & \\
\hline Zinc & Air & 9 & 7 & 6 & 8 & 8 & & 4 \\
\hline Hydrogen-3 & Air & 3 & 10 & 6 & 13 & 15 & 56 & \\
\hline Benzene & Air & 8 & 6 & 5 & 5 & 5 & & \\
\hline Nitrogen dioxide & Air & 5 & 5 & 7 & 3 & 3 & & 13 \\
\hline Sulfur dioxide & Air & 3 & 3 & 3 & 3 & 3 & & 9 \\
\hline Methane & Air & 3 & 2 & 3 & 1 & 1 & 2 & 9 \\
\hline Lead & Air & 3 & 2 & 2 & 3 & 2 & & \\
\hline Chlorpyrifos & Agri-soil & 1 & 2 & 3 & 1 & 1 & & \\
\hline Nitrous oxide & Air & 2 & 1 & 2 & & & & 21 \\
\hline Particles (PM10) & Air & 2 & 1 & 1 & 1 & 1 & & 1 \\
\hline Atrazine & Agri-soil & 1 & 2 & 2 & 1 & 1 & & \\
\hline Iodine-131 & Air & 1 & 2 & 1 & 3 & 4 & 13 & \\
\hline Chlorothalonil & Agri-soil & 1 & 1 & 2 & 1 & 1 & & \\
\hline Non-methane VOC & Air & 1 & 1 & 2 & 1 & 1 & & 2 \\
\hline Phosphate & Water & 1 & 1 & 2 & 4 & 4 & & \\
\hline Formaldehyde & Air & 2 & 1 & 1 & 1 & 1 & & \\
\hline Cyanazine & Agri-soil & 1 & 1 & 1 & & & & \\
\hline Total & & 85 & 86 & 84 & 84 & 86 & 97 & 94 \\
\hline
\end{tabular}


low. For example, $\mathrm{C} 14$ and hydrogen-3 belong to the highest ranking emissions, as the combined effect of the characterisation score of $\mathrm{C} 14$ and hydrogen-3 as a radioactive emission, and the weight of radiation in the weighted score. So, the question is, whether or not this is correct. Is the estimated emission too high? Or is there a mistake in the impact assessment, in the characterisation factor or weighting factor for ionizing radiation? ReCiPe damage cost seems to be completely dominated by damages to ecosystem health caused by radiation and emissions of $\mathrm{CO}_{2}$. Again, this might be caused by an incorrect modelling in the characterisation from midpoint to endpoint indicators and/or by weight set too high in the valuation of damages to ecosystems. The impact score based on NEEDS is completely dominated by the emissions of GHG that make up $60 \%$ of the impact score. Table 4 shows the contribution of interventions to the total impact score for each method.

\section{Discussion}

Quite some second-best choices have been made in developing the meta-weighting set. When interpreting the results of the seven presented impact assessment and weighting sets several comments can be made which underline that the presented results should be considered preliminary and that further development of both the characterisation and weighting is necessary. There is incompleteness in modelling. The present version of the ILCD Handbook recommended characterisation lacks the assessment of two impact categories, land use and water depletion, that in principle should be considered. NEEDS focuses only on air emissions of GHG and classical bulk emissions to air. Important missing impact categories are damage to ecosystems by toxic releases, land use and depletion of water. The last two are, at the moment, also missing in the ILCD characterisation. These omissions are partly recovered by data transfer using ILCD factors as extrapolation factors. The consequence of this data transfer is that the impact assessment will resemble ILCD-based impact assessment for these extrapolated NEEDS data.

The available modelling seems inconsistent is several respects. The midpoint to endpoint modelling as indicated conceptually in ILCD seems not to have been completely elaborated for ecosystem health, in any method. There is no consistent set of endpoint indicators yet. In this weighting project a rough provisional conversion is applied in order to be able to aggregate the scores in an equitable way, and in order to link methods. This rough provisional conversion might be the explanation of some of the oddities in the preliminary results. Also attention should be given to de modelling of ionizing radiation because the present characterization factors results in an unexpected high contribution of radioactive emissions to the total environmental impact score, due to $\mathrm{C} 14$ emissions.

Some further consistency aspects should be considered when evaluating scores based on characterisation models. The evaluation of scores will become complex when they have to reckon with inconsistencies between the characterisation models used for different impact categories, like differences in time scale and/or geographical scale of the effect and whether or not background concentrations are taken into account. In the present set of ILCD characterisation factors for example, the impact assessment of climate change is based on a specified time horizon (e.g., 100 years), while, by contrast, fate modelling for the toxicity scores is based on an infinite time horizon, without discounting. Integrated modelling has a long time horizon but then discounts. How discounting might fit into LCA is an open question (see Hellweg et al. 2003). On a geographical scale there are differences between the global models, like climate change and ozone depletion and the continental or local models, like acidification and eutrophication. Finally, background concentrations are taken into account in climate change and ozone depletion models but not in characterisation of the other impact categories like in toxicity and eutrophication. Hence, the evaluation of assumed effects (midpoint weighting) or the further modelling of effects (endpoint weighting) can hardly be consistent in this respect. As time and place, integrated approaches tend to have a more well-defined treatment, with quite some underlying disagreement at a more detailed level, for example as to the discount rates to be used. As we added toxicity to the integrated modelling based on LCA-type reasoning, some inconsistency definitely is involved.

In the integrated modelling and weighting, different costs are used to valuate different endpoints (human health, ecosystem health (i.e., eutrophication and acidification), global warming and radiation. These involve conceptually different options like willingness-to-pay and reduction costs. Weighting across endpoints then is not consistent, not in terms of decision support where choices on allowable cost are involved. This point has been resolved as much as possible by using willingness-to-pay as the only base method in economic valuation.

\section{Conclusions}

For the overall judgement on future impacts of sets of environmental interventions, weighting based on explicit evaluation methods seems to be the most appropriate approach, surely as compared to unspecified and ill-communicated methods, and the more so as compared to unsubstantiated choices. Reluctance on using quantified evaluation methods, as often encountered in ecological economics, is understandable but not a valid position if specific choices are to be made. 
Discussion on explicit weighing is the more important as there is not one right method, nor will one method be generally accepted. Different weighting methods each have their relative strengths and weaknesses. Selecting one as the best therefore is not possible. The best approach for now is to explicitly combine the three different approaches for evaluation, using relative pure methods, into a single metaweighting method, showing the contribution of each underlying method, and showing where they agree and differ in the case at hand. The combined method transforms the environmental interventions via environmental effects into one environmental indicator score, as an overall evaluation. As there is no best single method, the combined weighting method should easily be varied as to the contribution of the individual methods in determining the outcome. It now can create a "best weighting-related practice."

The application to a time series of aggregate European data shows that there is no wide divergence between the different weighting methods when applied to such macro level data. This means that the choice of specific weighting methods may not have an overarching influence on outcomes and the combined set of meta-weights reasonably reflects different positions in weighting. When applied at cases at a micro level, the methods will diverge more.

The two-step procedure of first weighing environmental aspects into an overall score and next relating this score to cost and value creation is not recommended in multi-criteria analysis. A single overall evaluation step is recommended there. The two-step procedure seems a most practical approach for now, however, next linking the two domains loosely as in eco-efficiency analysis. This also is the case due to differences in effect modelling between the two domains. Improving the effect modelling behind underlying impact categories is well possible, then leading to adapted characterisation factors. The change and addition of new midpoint impact categories would require new weighting procedures, for all methods. The state of the art in impact assessment and weighting is not final because of developments in modelling of effects and because of changes in subjective choices. Main deficiencies and inconsistencies in modelling and evaluation should be resolved, especially in the now quite chaotic treatment of time in different modelling steps and in terms of regional differentiation of effects.

An open discussion on the as yet ill developed environmental evaluation subject is due, also at a conceptual level, then making next steps in the sustainability discourse.

Open Access This article is distributed under the terms of the Creative Commons Attribution License which permits any use, distribution, and reproduction in any medium, provided the original author (s) and the source are credited.

\section{Appendix 1}

A spreadsheet translates emissions into the three main evaluation methods, which can be combined into a single score using a meta-weighting set. It can be downloaded from: http://www.leidenuniv.nl/cml/ssp/databases/weighting/ weighting_environmental_impacts_metamethod_ version_1.0.zip.

\section{References}

Ackerman F, Heinzerling L (2004) On knowing the price of everything and the value of nothing. The New Press, New York

Ahlroth S (2009) Valuation of environmental impacts and its use in environmental systems analysis tools. PhD dissertation 2009-102, Environmental strategies Research, KTH

Ahlroth S, Finnveden G (2009) Ecovalue08 - a new valuation method for environmental systems analysis tools. In: Ahlroth S (ed) Valuation of environmental impacts and its use in environmental systems analysis tools. Doctoral thesis, KTH, Stockholm

Anonymous (1987) Our Common Future, Report of the World Commission on Environment and Development, World Commission on Environment and Development, 1987. Published as Annex to General Assembly document A/42/427. Development and International Co-operation: Environment August 2, 1987, and by Oxford Press 1987

Arrow KJ (1950) A difficulty in the concept of social welfare. J Polit Econ 58(4):328-346

Bengtsson M, Steen B (2000) Weighting in LCA — approaches and applications. Environ Prog Sustain Energ 19(2):101-109

de Bruyn S, Korteland M, Markowska A, Davidson M, de Jong F, Bles M, Sevenster M (2010) Shadow prices handbook. Valuation and weighting of emissions and environmental impacts. CE, Delft. http://www.ce.nl/publicatie/handboek_schaduwprijzen_\%3A waardering_en_weging_van_emissies_en_milieueffecten/1027

EC-JRC (European Commission-Joint Research Centre) (2010a) International Reference Life Cycle Data System (ILCD) Handbook - framework and requirements for Life Cycle Impact Assessment models and indicators. European Commission-Joint Research Centre - Institute for Environment and Sustainability (IES). Retrieved from http://lct.jrc.ec.europa.eu/pdf-directory/ ILCD-Handbook-LCIA-Framework-requirements-online12March2010.pdf

EC-JRC (European Commission-Joint Research Centre) (2010b) International Reference Life Cycle Data System (ILCD) Handbook - analysis of existing environmental impact assessment methodologies for use in Life Cycle Assessment. European Commission-Joint Research Centre - Institute for Environment and Sustainability (IES). Retrieved from http:// 1ct.jrc.ec.europa.eu/pdf-directory/ILCD-Handbook-LCIABackground-analysis-online-12March2010.pdf

EC-JRC (European Commission-Joint Research Centre) (2011) International Reference Life Cycle Data System (ILCD) Handbook-Recommendations for Life Cycle Impact Assessment in the European Union based on existing environmental impact assessment models and factors. European Commission-Joint Research Centre-Institute for Environment and Sustainability (IES). Retrieved from http://lct.jrc.ec.europa.eu/pdf-directory/ Recommendation-of-methods-for-LCIA-def.pdf

Eldh P (2003) Ecotax02-An update of a Life Cycle Assessment weighting method. With a case study on waste management. MSc thesis, TRITA-KET-IM 2003:12, Stockholm 
ETDS, the Environmental Terminology and Discovery Service of the European Environment Agency; on DPSIR see their website: http://glossary.eea.europa.eu/terminology/concept_html? term $=$ dpsir

Finnveden G (1997) Valuation methods in LCA-where are the values? Int J Life Cycle Assess 2(3):163-169

Finnveden G (1999) A Critical Review of Operational Valuation/ Weighting Methods for Life Cycle Assessment, Survey. FMS, Stockholm, AFR-REPORT 253, ISSN 1102-6944 ISRN AFR$\mathrm{R}-\mathrm{-253}$ - SE

Finnveden G, Eldh P, Johansson J (2006) Weighting in LCA based on ecotaxes - development of a mid-point method and experiences from case studies. Int J Life Cycle Assess 11(1):81-88, special issue

Frischknecht R, Steiner R, Jungbluth N (2008) Ökobilanzen: Methode der ökologischen Knappheit - Ökofaktoren 2006. Methode für die Wirkungsabschätzung in Ökobilanzen. Öbu SR 28/2008. Öbu, Zürich, Switserland http://www.oebu.ch/oebu/downloads/ oekofaktoren_sr28.pdf

Goedkoop M, Spriensma R (2000) The Eco-indicator 99, a damage oriented method for Life Cycle Impact assessment, Methodology Annex. Pre Consultants b.v., Amersfoort, The Netherlands

Hauschild M, Wenzel H (1998) Environmental assessment of products. Vol. 2 Scientific background. Chapman \& Hall, United Kingdom/ Kluwer Academic Publishers, Hingham, MA, USA. pp 565

Heijungs R (2008) The weighting step in life cycle impact assessment. Three explorations at the midpoint and endpoint level. Weighting with damage costs. CML, Leiden University, Netherlands

Heijungs R et al (1992) Environmental Life Cycle Assessment of Products: Guide and Backgrounds. CML, Leiden, downloadable at: https://openaccess.leidenuniv.nl/handle/1887/8062

Hellweg S, Hofstetter TB, Hungerbühler K (2003) Discounting and the environment. Should current impacts be weighted differently than impacts harming future generations? Int $\mathrm{J}$ Life Cycle Assess 8 (1):8-18

Higgins AJ, Hajkowicz S, Bu E (2008) A multi-objective model for environmental investment decision making. Comput Oper Res 35 (1):253-266

Hofstetter P (1998) Perspectives in life cycle impact assessment: a structured approach to combine models of the technosphere, ecosphere and valuesphere. ETH, Zurich

Huijbregts MAJ, Rombouts LJA, Hellweg S, Frischknecht R, Dik van de Meent JH, Ragas AMJ, Reijnders L, Struijs J (2006) Is cumulative fossil energy demand a useful indicator for the environmental performance of products? Environ Sci Technol 40:641-648

Huppes G, van Oers L (2011a) Evaluation of Weighting Methods for Measuring the EU-27 Overall Environmental Impact. JRC Scientific and Technical Reports, Luxembourg: Publications Office of the European Union. ISBN 978-92-79-21643-5, ISSN 1831-9424, doi: 10.2788/88465. Available at: http:// publications.jrc.ec.europa.eu/repository/handle/111111111/ 22702 Accessed January 2012

Huppes G, van Oers L (2011b) Background Review of Existing Weighting Approaches in Life Cycle Impact Assessment (LCIA). JRC Scientific and Technical Reports. Publications Office of the European Union, Luxembourg. ISBN 978-92-7921751-7, ISSN 1831-9424. doi: 10.2788/88828. Available at: http://lct.jrc.ec.europa.eu/pdf-directory/ReqNo-JRC67216-LBNA-24985-EN-N.pdf. Accessed January 2012

Huppes G, Davidson MD, Kuyper J, van Oers L, Udo de Haes HA, Warringa G (2007) Eco-efficient environmental policy in oil and gas production in The Netherlands. Ecol Econ 61(1):43-51

Itsubo N, Sakagami M, Washida T, Kokubu K, Inaba A (2004) Weighting across safeguard subjects for LCIA through the application of conjoint analysis. Int J Life Cycle Assess 9(3):196-205
Lippiatt BC (2007) BEES 4.0. Building for Environmental and Economic Sustainability Technical Manual and User Guide. National Institute of Standards and Technology (NIST), Gaithersburg, USA. http://www.bfrl.nist.gov/oae/software/bees/

Lundie S, Huppes G (1999) Environmental assessment of products: the ranges of societal preferences method. Int J Life Cycle Assess 4 (1):7-15

Mettier TM, Hofstetter P (2005) Survey insights into weighting environmental damages. influence of context and group. J Ind Ecol 8:189-209

von Neumann J, Morgenstern O (1944) Theory of games and economic behavior, 1953rd edn. Princeton University Press, Princeton

Norris G (2001) The requirement of congruence in normalisation. Int J Life Cycle Assess 6(2):85-88

Notarnicola B, Huppes G, van den Berg NW (1998) Evaluating options in LCA: the emergence of conflicting paradigms for impact assessment and evaluation. Int J Life Cycle Assess 3(5):289-300

Powell JC, Pearce DW, Craighill AL (1997) Approaches to valuation in LCA impact assessment. Int J Life Cycle Assess 2(3):163-169

Preiss P, V. Klotz V (2008) NEEDS New Energy Externalities Developments for Sustainability. Technical Paper no. 7.4 - RS 1b. Description of updated and extended draft tools for the detailed site-dependent assessment of external costs. Universität Stuttgart, Germany. http://www.needs-project.org/

Preiss P, Friedrich R, Klotz V (2008) NEEDS new energy externalities developments for sustainability. Deliverable $\mathrm{n}^{\circ} 1.1-\mathrm{RS}$

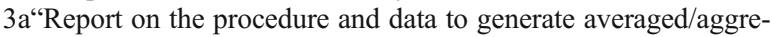
gated data" Institute of Energy Economics and the Rational Use of Energy. (IER) Department of Technology Assessment and Environment (TFU) University of Stuttgart. http://www.needsproject.org/ and http://ecosenseweb.ier.uni-stuttgart.de/

Rawls J (1971) A Theory of Justice. Cambridge (MA): Belknap Press

Sas H, Huppes G, de Haan E, Kuyper J (1996) Weegfactoren voor bedrijfsmilieuplannen NOGEPA, Report of the Workshop d.d. 23/ 24-11-1995. Delft: Centrum voor Energiebesparing, 37 pp, mei 1996. 's-Gravenhage: NOGEPA

Scholz RW, Tietje O (2002) Embedded case study methods. Integrating quantitative and qualitative knowledge. Sage Publications, Thousand Oaks

Sen A (1970) Collective choice and social welfare. San Francisco: Holden Day

Soares SR, Toffoletto L, Dechênes L (2006) Development of weighting factors in the context of LCIA. J Cleaner Prod 14:649-660

Steen B (1999a) A systematic approach to environmental priority strategies in product development (EPS). Version $2000-$ General system characteristics. CPM report 1999:4. CPM, Chalmers university, Göteborg, Sweden

Steen B (1999b) A systematic approach to environmental priority strategies in product development (EPS). Version $2000-$ Models and data of the default method. CPM report 1999:5. CPM, Chalmers university, Göteborg, Sweden

Stern N (2007) The economics of climate change. The Stern review. Cambridge University Press, Cambridge

Tol RSJ (2006) NEEDS New Energy Externalities Developments for Sustainability. Technical Paper no. 5.4/5.5 - RS 1b. "Report on marginal external costs inventory of greenhouse gas emissions" and "Report on the analysis on average and marginal avoidance costs of greenhouse gas emissions". Hamburg University, Germany. http://www.needs-project.org/

Tol RSJ (2008) The Social Cost of Carbon: Trends, Outliers and Catastrophes. Economics: The Open-Access, Open-Assessment E-Journal, Vol. 2, 2008-25. http://www.economics-ejournal.org/ economics/journalarticles/2008-25

Turner G, Handley D, Newcombe J, Ozdemiroglu E (2004) Valuation of the external costs and benefits to health and environment of waste management options. Final report for Defra by Enviros Consulting 
Limited in association with EFTEC. London: DEFRA Available at: http://archive.defra.gov.uk/environment/waste/statistics/documents/ costbenefit-valuation.pdf Accessed January 2012

Van der Voet E, van Oers L, Moll S, Schütz H, Bringezu S, de Bruyn S, Sevenster M, Warringa G (2005) Policy review on decoupling: development of indicators to assess decoupling of economic development and environmental pressure in the EU-25 and AC-3 countries. CML report 166. Leiden, The Netherlands: Institute of Environmental Sciences (CML), Leiden University. http://cml. leiden.edu/publications/publications-ie.html\#2009

Van der Voet E, van Oers L, de Bruyn S, de Jong F, Tukker A (2009) Environmental Impact of the use of Natural Resources and Products. CML report 184. Department of Industrial Ecology. 186p. http:// cml.leiden.edu/publications/publications-ie.html\#2009

Vogtländer J, Baetens B, Bijma A, Brandjes E, Lindeijer E, Segers M, Witte F, Brezet JC, Hendriks CF (2009) + LCA-based assessment of sustainability The Eco-costs/Value Ratio: EVR Delft: 2009/xiv + 219 pp

Wackernagel M, Monfreda C, Moran D, Wermer P, Goldfinger S, Deumling D, Murray M (2005) National footprint and biocapacity accounts 2005: the underlying calculation method. Global Footprint Network, Oakland

Wegener Sleeswijk A, van Oers LFCM, Guinée JB, Struijs J, Huijbregts MAJ (2008) Normalisation in product life cycle assessment: an LCA of the global and European economic systems in the year 2000. Sci Total Environ 390(1):227240

Weidema BP (2009) Using the budget constraint to monetarise impact assessment results. Ecol Econ 68:1591-1598

Weitzman ML (1999) Pricing the limits to growth from minerals depletion. Q J Econ 114(2):691-706, MIT Press

Weitzman ML (2009) On modeling and interpreting the economics of catastrophic climate change. Rev Econ Stat 91(1):1-19

Wenzel H, Hauschild MZ, Alting L (1997) Environmental assessment of products. Vol. 1. Chapman \& Hall, United Kingdom/Kluwer Academic Publishers, Hingham, MA, pp 544

Zhang Z, Wu X, Yang X, Zhu Y (2006) BEPAS - a life cycle building environmental performance assessment system. Build Environ 41:669-675 